\title{
Endoscopic management of perforations, leaks and fistulas
}

\author{
Ritu Raj Singh, Jeremy S. Nussbaum, Nikhil A. Kumta \\ Dr. Henry D. Janowitz Division of Gastroenterology, Icahn School of Medicine at Mount Sinai, New York, NY, USA \\ Contributions: (I) Conception and design: All authors; (II) Administrative support: All authors; (III) Provision of study materials or patients: All \\ authors; (IV) Collection and assembly of data: All authors; (V) Data analysis and interpretation: All authors; (VI) Manuscript writing: All authors; (VII) \\ Final approval of manuscript: All authors. \\ Correspondence to: Nikhil A. Kumta, MD, MS. Director of Surgical and Bariatric Endoscopy, Icahn School of Medicine at Mount Sinai, Dr. Henry D. \\ Janowitz Division of Gastroenterology, One Gustave L. Levy Place, Box 1069, New York, NY 10029, USA. Email: Nikhil.Kumta@gmail.com.
}

\begin{abstract}
The endoscopic management armamentarium of gastrointestinal disruptions including perforations, leaks, and fistulas has slowly but steadily broadened in recent years. Previously limited to surgical or conservative medical management, innovations in advanced endoscopic techniques like natural orifice transluminal endoscopic surgery (NOTES) have paved the path towards development of endoscopic closure techniques. Early recognition of a gastrointestinal defect is the most important independent variable in determining successful endoscopic closure and patient outcome. Some devices including through the scope clips and stents have been well studied for other indications and have produced encouraging results in closure of gastrointestinal perforations, leaks and fistulas. Over the scope clips, endoscopic sutures, vacuum therapy, glue, and cardiac device occluders are other alternative techniques that can be employed for successful endoscopic closure.
\end{abstract}

Keywords: Endoscopic closure; endoscopic suturing; over-the-scope clip (OTSC); cardiac septal defect occluder; perforation; leak; fistula

Received: 26 August 2018; Accepted: 19 October 2018; Published: 31 October 2018.

doi: $10.21037 /$ tgh.2018.10.09

View this article at: http://dx.doi.org/10.21037/tgh.2018.10.09

\section{Introduction}

In recent years there has been a surge in the evolution of interventional endoscopic techniques, notably natural orifice transluminal endoscopic surgery (NOTES), endoscopic submucosal dissection (ESD), per-oral endoscopic myotomy (POEM), and endoscopic full-thickness resection (EFTR) for the management of various benign and malignant conditions of the gastrointestinal (GI) tract (1-3). While these advances in therapeutic endoscopic procedures have provided a less invasive approach to managing a broad range of GI pathologies, they have contributed to the rising incidence of GI tract disruptions. At the same time, widespread use of laparoscopic and bariatric surgical procedures has also contributed to the rising incidence of GI defects, notably anastomotic leaks, perforations and marginal ulcers (4-6). In addition, non-iatrogenic injuries and various GI pathologies contribute to a proportion of GI disruptions, like perforations, leaks and fistulas. These innovative interventional endoscopic techniques have accelerated the development of endoscopic closure techniques such as clipping, stenting, suturing, gluing and endoscopic vacuum therapy. These minimally invasive closure techniques have revolutionized the management of GI defects, providing a more affordable alternative to surgery with less morbidity and resource utilization. Most iatrogenic endoscopically encountered perforations or leaks are best managed during the same session. In this paper, we will review the currently available endoscopic closure techniques for GI perforations, fistulas and leaks.

\section{Grades/types of gastrointestinal defects: definitions}

Perforation is a full-thickness defect in the GI wall that occurs spontaneously or more commonly as a result of 
an injury, iatrogenic or traumatic. Certain locations in the GI tract are more vulnerable to such injury resulting in perforation. GI fistula is an abnormal epithelialized communication between two or more GI lumens or organs as a result of pathology or artificially created for enteral feeding. They can be internal (between GI organs) or external (between GI tract and body surface). A GI leak is an abnormal communication between an intra-luminal compartment and the surrounding space as a result of defect in the continuity of the wall, most commonly at the site of surgical anastomosis causing leakage of luminal contents. Leaks can be intra- or extra-peritoneal depending on the site of anastomosis and risk factors.

\section{Upper GI defects/disruption}

\section{Esophageal defects}

Esophageal perforation is characterized by transmural disruption in the esophageal wall with leakage of luminal contents into the surrounding mediastinal or peritoneal space, resulting in local and/or systemic inflammatory response. Although uncommon, the esophagus is a frequent site of perforation in the GI tract and mostly results from iatrogenic injury during endoscopic or laparoscopic procedure. It accounts for about half of the perforations resulting from upper endoscopy (7). The highest incidence of esophageal perforations is reported following laparoscopic foregut surgeries, with rate as high as $14 \%$ from re-operation for hiatal hernia followed by laparoscopic antireflux surgery (4.2\%) (4). Diagnostic upper endoscopy has a low risk of perforation $(0.03 \%)$ with esophagus contributing to the majority (7). ESD, endoscopic mucosal resection (EMR) and balloon or bougie dilation for the treatment of esophageal strictures are iatrogenic injuries with higher incidence of perforation, $0.6 \%$ to $1.9 \%$ per procedures $(1,8,9)$. Other endoscopic procedures rarely associated with perforation include diagnostic transesophageal echocardiography (TEE) and esophageal biopsy (10).

Non-iatrogenic causes of perforation include spontaneous perforation in a diseased esophagus or Boerhaave syndrome, and those related to foreign body or external trauma. Mortality rate from esophageal perforation varies between studies with two large retrospective studies showing $12-30 \%$ 30-day mortality rates. The most important prognostic factor in these studies was early recognition and treatment in the first 24 hours. Another important factor determining mortality was health of the underlying esophagus. Emergency surgical treatment is associated with increased mortality (11-13).

\section{Esophageal/esophagogastric leaks}

Anastomotic leak is one of the most common causes of increased mortality and extended hospital stay following esophagectomy. Large retrospective studies have reported anastomotic leaks rates of $8-10 \%$ following esophagectomy with mortality rates of $10-20 \%$ depending on the surgical approach and medical comorbidities, notably-obesity, heart failure, vascular disease, diabetes and renal insufficiency. Patients who require surgical management have higher mortality compared to those managed medically $(14,15)$.

\section{Esophageal fistulas}

Esophageal fistulas in adults are almost exclusively acquired, and are mostly malignant or the result of prolonged mechanical ventilation. Most of the fistulous communication is with the trachea [tracheoesophageal fistula (TEF)], less commonly bronchus (bronchoesophageal, BEF) and rarely lung parenchyma (esophagopulmonary fistula). Patient with esophageal cancer will develop a fistula in $5-12 \%$ of cases while less than $1 \%$ of those with lung cancer develop fistulas (16-19). Radiation and chemotherapy/immunotherapy (Bevacizumab) have been also linked in the causality of malignant TEF or $\operatorname{BEF}(20,21)$.

Benign TEF occurs most commonly following prolonged intubation from cuff related injury (22). Other etiologies of benign esophageal fistula include esophageal injuriestraumatic or iatrogenic, following surgery or endoscopic interventions.

Diagnosis of the fistula can be delayed due to the symptoms being non-specific and expected in patients with the underlying predisposing conditions. Definitive diagnosis can be achieved by fluoroscopic demonstration of fistulous communication following water-soluble contrast swallow. It can also provide accurate information about the size and topography of the fistula. Endoscopy and/or bronchoscopy aids in further confirmation and localization of the fistula.

\section{Gastroduodenal defects}

Most gastroduodenal perforations result from peptic ulcer disease, while less common causes include gastric malignancy, foreign body, or external trauma. Iatrogenic gastric perforation most commonly results following ESD and less often EMR. ESD carries the highest incidence, 
$1.2-5 \%$ per procedure. The risk is higher for upper and middle third of stomach, particularly greater curvature $(2,23)$. Duodenum is the second most common site of upper endoscopy related perforation (32\% of perforations), after esophagus (7).

Although rare, ERCP is a major cause of iatrogenic duodenal perforation and occurs in $0.8-1 \%$ of cases, with most around the ampulla $(24,25)$. Periampullary perforations have been divided into 4 types, duodenal wall (type 1), peri-Vaterian (type 2), pancreatic or bile duct (type 3) and isolated retroperitoneal air (type 4) (26).

Gastroduodenal fistulas are iatrogenic in most instances ( $95 \%$ of cases) with majority occurring after surgery, however they account for a small proportion of GI fistulas (27). Other less common etiologies are trauma and malignancy. The majority of the malignant fistula distal to the esophagus arise from colon cancer and rarely, gastric cancer. Crohn's disease has been reported in handful of cases to have caused gastric or duodenal fistula. Small bowel perforation or fistula is rare in the absence of underlying Crohn's disease or lymphoma complicating celiac disease. Endoscopic management of such perforations or fistulas is challenging (28).

Gastrocutaneous fistula can occur following removal of percutaneous endoscopic gastrostomy (PEG) tube placed for feeding or gastric decompression. Rarely, the tract does not close leading to a persistent gastrocutaneous fistula in $\sim 1 \%$ of patients $(29,30)$.

\section{Bariatric surgery related defects}

Gastrojejunal leaks following RYGB procedures is seen in $0.3-8 \%$ of cases, one of the largest series by Nguyen $e t a l$. reported rates of $\sim 2 \%$ with both open and laparoscopic procedures $(5,6)$. Another common defect following RYGB is gastro-gastric fistula (between excluded stomach and the gastric pouch), which was seen in $1.2 \%$ cases in a review of $\sim 1,300$ patients (6). Gastric staple-line leak and less commonly fistula can be seen following sleeve gastrectomy (31).

\section{Lower GI defects}

Anastomotic leakage has been observed in $~ 11 \%$ of patients undergoing surgery for colorectal cancer and has a mortality rate as high as $12 \%$ (32). Proctocolectomy and total mesorectal excision followed by creation of ileoanal or coloanal anastomosis is commonly performed on cancer patients. These two procedures can have rates of leakage up to $20 \%$ (33). Predisposing factors include age, male sex, smoking, coronary heart disease, obesity, or difficult anastomosis (34).

Lower GI perforations can be iatrogenic or spontaneous. Spontaneous perforation of the colon is fairly uncommon but can be seen following mechanical obstruction and in patients with inflammatory bowel disease (IBD) or diverticulitis. Intestinal perforation in patients with IBD usually occurs during acute exacerbations (35). Diverticulitis is the most common cause of spontaneous colonic perforation (36). Iatrogenic colonic perforation is encountered during diagnostic or therapeutic colonoscopy. Perforation during diagnostic colonoscopy can be caused by pressure from the endoscope against the colonic wall or over-insufflation of the colon. During diagnostic colonoscopy, the most common sites of perforation are the sigmoid colon and rectosigmoid junction with perforation rate of $0.03-0.8 \%$ (37). Colonoscopies are 10 times more likely to have serious complications if biopsy or polypectomy is performed (3). The European Society of Gastrointestinal Endoscopy (ESGE) names complex EMR, ESD and balloon dilation procedures as high risk for colorectal perforations (37). The rate of colonic perforation with ESD is $4-10 \%$. Polypectomy injury can occur when resecting polyps greater than $1 \mathrm{~cm}$ in the right colon or $2 \mathrm{~cm}$ in the left colon, resection of multiple polyps, or using argon plasma coagulation or electrocautery (3). Lower GI perforation can result in pneumoperitoneum, with the most serious consequences being tension pneumoperitoneum and abdominal compartment syndrome. Egress of luminal contents can also result in peritonitis.

Colonic fistulas often communicate with the bladder, vagina, and skin, and can be difficult to treat endoscopically. They are usually caused by diverticular disease, Crohn's disease, tumor, radiation therapy, or trauma. Gastrocolocutaneous fistula, a connection between the mucosa of the stomach, colon, and skin, is a rare complication that can develop following placement of $\mathrm{PEG}$ tube and is reported in about $0.5 \%$ patients (38).

\section{Diagnosis}

Early recognition of a GI defect is key to a better outcome. High degree of clinical suspicion is needed to detect a leak or perforation early after a procedure, endoscopic or laparoscopic. Perforations can be recognized early during endoscopy by loss of adequate luminal distention despite air insufflation, or delayed with pain and fever. Leaks 
Table 1 Perforation acronym: RAPID CLOSuRE

Recognition
Antibiotics
Position
I'm scared
Decompress
Carbon dioxide
Legal/Risk management
Observe/admit patient
Surgery consult
u
Radiology
Explain to patient/family

after surgery are identified by persistent drain output. While external or cutaneous fistula is recognized clinically, diagnosis of an internal fistula can be difficult and delayed. After initial clinical assessment of a suspected GI defect, imaging studies are needed to make a definitive diagnosis. Chest and abdominal radiographs can be useful in the initial workup; however, cross-sectional imaging with computed tomography (CT) scan, or fistulogram with water-soluble contrast is required for definitive diagnosis and anatomic delineation.

\section{Evolution in the management of GI defects}

Management of GI defects depends on the size, location and acuity of the defect. Acute GI perforation has evolved from a surgical to a medical emergency over the past several years with infrequent routine use of emergent surgical treatment. As more and more iatrogenic defects are recognized during the procedure itself, primary endoscopic closure is feasible. There has been a consistent trend towards nonsurgical management of these defects. In a 20-year analysis of esophageal perforations at a tertiary academic center by Kuppusamy et al. in 2011, there was a gradual decline in the proportion of operative treatment from $100 \%$ in $1989-1992$ to $25 \%$ in $2005-2009$. This was accompanied by a reciprocal increase in the use of endoscopic closure techniques from $38 \%$ to $80 \%$ (39). Another large, multicenter study of more than 2,500 esophageal perforations from England showed a trend towards non-surgical treatment continuing in the last decade, accompanied by significant reduction in mortality (13). Nevertheless, the role of surgery cannot be discounted in cases of large defects and those with failed endoscopic treatment or gross contamination of the visceral spaces. Laparoscopic and open surgical approaches for managing these defects have been compared in several studies including randomized trials and meta-analysis without any clear advantage of one over the other $(40,41)$.

\section{General tips on management}

Regardless of the choice of intervention for correcting a GI defect, early recognition and prompt medical management of post-procedural perforations and leaks are essential to good patient outcomes. Baron et al. described the "Ten Commandments of Endoscopic Perforations": (I) prompt recognition of perforation is essential; (II) presence of extraluminal air does not automatically mean the need for surgery; (III) volume of extraluminal air is not necessarily proportional to the size of the perforation (rather to the degree of air insufflation); (IV) extraluminal air per se is not infectious (egress of luminal contents is); (V) extraluminal air under pressure is a medical emergency (needle decompression may be necessary); (VI) extraluminal air can dissect into distant spaces; (VII) residual extraluminal air may persist without clinical significance; (VIII) perforations tend to close after drainage or diversion of luminal contents; (IX) free oral or injected contrast material extravasation should elicit prompt intervention; and (X) failed endoscopic closure of a perforation generally requires surgical intervention (42).

General measures in management of acute GI defects include nil per os (NPO), intravenous fluid as clinically indicated, antibiotic therapy and close hemodynamic monitoring. In addition, upper GI leaks and perforations also need acid-suppression therapy and nasogastric or nasoduodenal tube suctioning. Early enteral feeding (oral or tube) can be resumed in patients with uncomplicated postoperative course.

We have developed a pneumonic that can be utilized when perforations occur in the endoscopy suite. Think RAPID CLOSuRE when you encounter a GI perforation. The acronym has been illustrated in Table 1. The steps involve early recognition, proper positioning of the patient, switching to carbon dioxide for insufflation, and starting appropriate antibiotics. Patient needs to be admitted for observation with surgery consult for possible decompression or drainage if endoscopic therapy fails. Radiologic examination with contrast should be performed to confirm endoscopic closure of perforation. Emotions of anxiety and 
feeling scared are natural during iatrogenic perforations, but following appropriate steps can limit morbidity and legal obligations.

Patients being managed conservatively need more frequent clinical assessment of intrathoracic and/or intraperitoneal space for the development of compartment syndrome and need for emergent decompression. In addition, all patients need monitoring for signs of peritonitis or mediastinitis. These patients are at the highest risk of developing sepsis and organ failure, thus pre-emptive measures to avoid, or intervene early before development of overt signs of deterioration can be life-saving. Malnutrition and high GI output are common in these patients, particularly those with GI fistulas, hence the role of enteral or total parenteral nutrition (TPN) and suppression of GI secretion with a somatostatin analogue is worth mentioning (43).

\section{Endoscopic therapy}

\section{Devices and techniques Endoclips}

Clips are the most commonly used endoscopic modality in the closure of GI perforations (44). Two types of endoscopic clips are available, through-the-scope clip (TTSC) and over-the-scope clip (OTSC). TTSC is technically less demanding and can be used to close small defects $<1 \mathrm{~cm}$ while OTSC can provide full-thickness closure of defects up to $2 \mathrm{~cm}$ with single application, including those with everted edges. Originally developed to treat non-variceal GI bleeding, the use of OTSC over the years has expanded to include a wide variety of GI disruptions, reinforcement of stents, and prophylactic closure following polypectomy.

\section{Technique}

TTSC are usually applied in a serial parallel fashion for closure. Enhancing maneuvers like suctioning, to invert and approximate the edges, allows the wings of the clip to grasp the edges. Once the edges have been adequately approximated, the clip is deployed onto the grasped tissue (45).

OVESCO (OTSC ${ }^{\circledR}$, Ovesco Endoscopy GmbH, Tübingen, Germany) clip is the most widely used OTSC system. The OTSC hand wheel is inserted into the rubber valve on the working channel and attached to the endoscope using a Velcro strap. To apply the OTSC applicator cap to the distal end of the endoscope, the thread is pulled through the working channel of the endoscope. The OTSC is mounted onto the applicator cap. The OTSC can be deployed by using suction to draw the targeted tissue into the cap. Tissue approximation in a full-thickness singlelayer closure is accomplished by use of a twin grasper or a retractable tissue anchor set. Once the targeted tissue is entrapped by suctioning into the cap, the clip is deployed. It is important that the tissue is well targeted since a misplaced clip at the edge of a defect can complicate deployment of a subsequent clip if required $(46,47)$.

Another commercially available OTSC is the Padlock-G clip (Aponos Medical, Kingston, $\mathrm{NH}$ ) which utilizes a plastic cap with a preloaded clip at the tip of endoscope. It is a hexagonal nitinol ring with six inner needles and is deployed using a delivery system (48).

Both types of endoclips have their own limitations. TTSC's role is limited to smaller defects and has propensity for premature dislodgement. It is also associated with small leaks due to inadequate sealing and has a long procedure time which increases the risk of air-leak. The technical challenges of OTSC include the need to completely withdraw the endoscope to mount the device to the tip and the presence of a twin grasper with independently movable arms, especially with everted edges (49).

TTSC and OTSC have shown to be highly effective in managing iatrogenic perforations less than $2 \mathrm{~cm}$. A systematic review of literature on management of acute iatrogenic perforations by Yilmaz et al. showed technical success of $100 \%$ and clinical success ranging from $89 \%$ in colonic perforations to $98 \%$ of patients after ESD or EMR (50). It has been shown to be effective in management of gastric defects following EFTR with technical and clinical success in $100 \%$ of patients on short-term follow up (51).

\section{Endoscopic stents}

Stents have been widely used in the management of GI defects with excellent technical and clinical success. Esophageal and duodenal, less so colonic defects are amenable to stent closure. The available stents include selfexpanding metal stent (SEMS), fully covered metal stent (FSEMS) or partially covered metal stent (PSEMS), and self-expanding plastic stents metal stent (SEPS), however their use is off-label for benign disorders.

Covered metallic stents, especially FSEMS are the most commonly used endoscopic stents for GI defects (52-55). FSEMS have flares at both ends to reduce migration risk. Fluoroscopic control is facilitated by radiopaque markers at the ends of the stent. The size of the defect is determined endoscopically and subsequently a guide wire is introduced into the GI lumen. The stent is introduced via a delivery device over the guide-wire under fluoroscopic and/or endoscopic guidance. The stents are 
placed endoscopically under conscious sedation or general anesthesia. Clinical success has been observed in $76-83 \%$ of patients undergoing covered SEMS placement for benign upper GI perforations or leaks $(52,53,56)$. Although there is high risk of recurrence in patients with TEF, FSEMS has high technical and clinical success rate, $99 \%$ and $>90 \%$, respectively (57).

SEPS is an alternative to SEMS and the most common commercially available brand is PolyFlex (Boston Scientific, MA, USA). Stent placement is similar to SEMS. It has the advantage of easy repositioning and removal; however, it is associated with high migration rate. There is limited data on the use of SEPS for GI disruptions. Only one study has looked at the clinical success of SEPS, it was a retrospective analysis of 30 patients with post-surgical esophageal leaks and success was reported in 90\% (58). Other studies have included SEPS with SEMS and subgroup analysis of SEPS has showed success in up to $71 \%$ cases (52).

Stent migration, the major disadvantage of fully covered metal stents, has been reduced substantially with use of large-diameter stents, and reinforcing the stents with endoclips or endoscopic sutures (59-61). Another challenge is retrieval of embedded stents for which stent-in-stent technique and argon plasma coagulation have been tried $(62,63)$.

\section{Endoscopic suturing}

Endoscopic suturing has a variety of applications including stent fixation and closure of larger defects including fistula and perforations, but is technically more demanding. The OverStitch (Apollo Endosurgery Inc., Austin, TX, USA) is a disposable, single use stitching device that uses a double channel therapeutic endoscope to apply continuous or intermittent stitches without the need to remove the scope for reloading needles. Tissue approximation is facilitated by tissue-retracting device or grasping forceps and full thickness suturing is facilitated by a tissue helix catheter (47).

In a large multicenter retrospective study by Sharaiha et al., endoscopic suturing used for stent fixation, and closure of fistulas and perforations achieved high technical (97\%) and clinical success (79\%). The clinical success was sustained during 1 to 3 months of follow up without need for further intervention. While primary closure of acute fistulas (less than 30 days) following bariatric surgery has been highly successful, closure of chronic fistulas is disappointing with success rate as low as $23 \%$ (64).

\section{Cardiac septal occluders}

Atrial septal occluders (ASO), composed of two self- expandable disks are FDA approved for atrial septal defects. However, they have been shown in several case reports to be effective in treating GI fistulas including TEF $(65,66)$.

\section{Tissue adhesives and glue}

Fibrin glue and cyanoacrylate have been used with success in closure of surgical anastomotic leaks and low output fistulas. The glue is applied via a double lumen catheter after removal of any secretions or pus to dry the targeted area to form a fibrin clot. The underlying epithelium has to be denuded by APC or cytology brush prior to application. These tissue sealants can be used alone or in conjunction with other endoscopic modalities like clips (67).

\section{Endoscopic vacuum therapy (EVT) or EndoSponge}

Endoscopic drainage of extra-luminal (mediastinal/ peritoneal/pelvic) collection/abscess following an anastomotic leak or perforation can be managed with EVT. It has been shown to be effective in managing anastomotic leaks following esophageal as well as colorectal surgery. The technique involves placement of the endosponge at the intra-luminal portion of the defect or more commonly deep into the surrounding contaminated cavity via an overtube introduced through a standard endoscope. Multiple sponges can be used in case of larger cavity. The sponge is connected to a vacuum device with a constant pressure of $125-150 \mathrm{mmHg}$. The wound cavity collapses around the sponge with resulting evacuation of the cavity $(68,69)$.

\section{Preferred endoscopic modalities for GI defects Perforations}

Perforations of the GI tract are the defects most amenable to endoscopic therapy. As majority of perforations arise out of iatrogenic injury with underlying tissue being healthier and less friable, they can be managed with endoscopic approximation allowing for early healing. Various endoscopic approaches are available to seal the defect or limit the luminal communication during the same endoscopic setting if the perforation is detected during the procedure. Likewise, perforations arising out of Boerhaave syndrome or distal obstruction can be treated endoscopically as long as the extent of defect or access is not a limiting factor, given there is no gross contamination. The most important determinant of clinical outcome as outlined above is early recognition and closure of the defect (11-13). Various available endoscopic closure techniques for managing upper GI defects have been outlined in Table 2.

Once a perforation is detected during endoscopy, 
Table 2 Endoscopic modalities for managing upper gastrointestinal defects

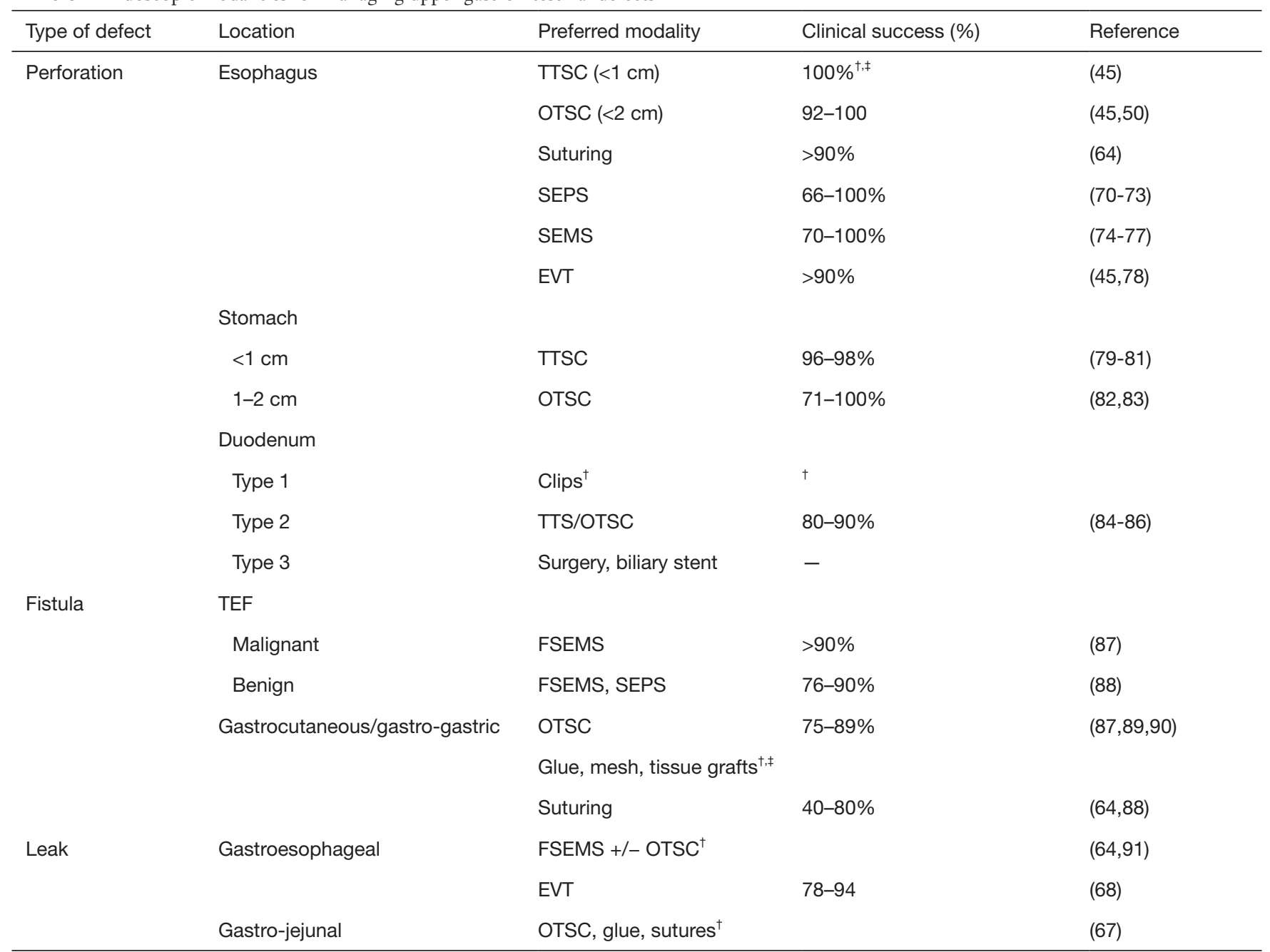

\footnotetext{
${ }^{\dagger}$, limited data; ${ }^{\ddagger}$, case reports/case series/pooled analysis. TTSC, through-the-scope clip; OTSC, over-the-scope clip; SEPS, selfexpandable plastic stent; FSEMS, fully-covered self-expandable metal stent; EVT, endoscopic vacuum therapy.
}

immediate attempt should be made to switch the gas to carbon dioxide $\left(\mathrm{CO}_{2}\right)$ for insufflation if not already in use as it is less irritating and can rapidly diffuse after closure of the defect compared with air. Close hemodynamic monitoring is warranted throughout the procedure for signs of tension pneumothorax or pneumoperitoneum.

Small esophageal defects $<2 \mathrm{~cm}$ can be managed with clips, sutures or adhesives while larger defects or perforations associated with everted edges may need FSEMS. Simultaneous internal drainage can be achieved with endoscopic vacuum therapy (EVT) $(9,11,12)$.

Traditional TTS clips are the mainstay of management of small gastric defects (less than $1 \mathrm{~cm}$ ), with successful closure in over $98 \%$ of cases $(79,92)$. Gastric defects greater than $1 \mathrm{~cm}$ has been managed with omental patch prior to clip application (79). Larger defects are managed with OTS clips and clip-loop method which utilizes multiple peripheral TTS clips for approximation (93). OverStitch (Apollo Endosurgery Inc., Austin, TX, USA) has been shown in small series to be effective in the management of marginal ulcers and gastric defects following ESD $(94,95)$. Endoscopic suturing has also been used for closure of gastric defects, however the data is limited. Animal studies have provided some insight into the successful use of suturing gastric defects up to $2 \mathrm{~cm}(96,97)$.

Duodenal perforations unlike rest of the upper GI perforations are difficult to manage endoscopically with majority requiring surgical closure. Type 1 periampullary 
Table 3 Endoscopic modalities for managing colonic defects

\begin{tabular}{|c|c|c|c|}
\hline $\begin{array}{l}\text { Type of } \\
\text { defect }\end{array}$ & Preferred modality & $\begin{array}{l}\text { Clinical success } \\
\text { rate }(\%)\end{array}$ & References \\
\hline Perforation & Clips (TTSC, OTSC) & $70-91 \%$ & $(97,100-103)$ \\
\hline Fistula & OTSC & $71-89 \%$ & (89) \\
\hline \multirow[t]{3}{*}{ Leak } & OTSC & $84.6 \%$ & (104) \\
\hline & SEMS & $71.4 \%$ & (104) \\
\hline & Endo-Sponge & $94.3 \%$ & (69) \\
\hline
\end{tabular}

TTSC, through-the-scope clip; OTSC, over-the-scope clip; SEPS, self-expandable plastic stent; FSEMS, fully-covered selfexpandable metal stent; EVT, endoscopic vacuum therapy.

perforations resulting from ERCP are usually large and require surgical correction while type 2 perforations have been managed with TTSC or biliary stent along with nasoduodenal drain. However, $10-40 \%$ of the defects end up requiring surgery. Bile duct injuries can be easily managed with temporary plastic stent or fully covered SEMS. Non-periampullary perforations usually result from injuries related to scope manipulation and endoscopic management is limited by access and difficulty with deployment of clips. Despite this, there have been reports of successful use of TTS and OTS clips for these defects $(25,26,84-86,98,99)$.

Colonic perforations resulting from diagnostic colonoscopy occur in $0.01-0.3 \%$ and are predominantly (about $2 / 3$ cases) in the sigmoid colon. Therapeutic procedures related perforations are located in the cecum and right side of colon and arise as a result of transmural electrocautery, polypectomy or ESD with rate of $1.2-5 \%$. Initial management includes decompression of the peritoneal cavity. Further management depends on the time of detection, site and size of the defect. Small perforations, less than $2 \mathrm{~cm}$ detected in the peri-procedural period can be managed with TTS or OTS clips while larger defects require endoscopic suturing or rarely surgery. Close monitoring is required for clinical deterioration and development of persistent leak. CT scan of abdomen with rectal contrast can be useful for rectal or distal colonic perforations $(100,101)$. Table 3 outlines endoscopic methods for closure of colonic defects.

\section{Leaks}

Early management of leaks is dependent on whether there is an extraluminal drain that can limit mediastinal and/or peritoneal contamination. Infection is almost inevitable in the absence of a surgical drain, which should be placed prior to closure of the leak. Esophagogastric leak following Ivor-Lewis procedure is one of the most common sites of anastomotic leak $(14,15)$. Endoscopic isolation of the leakage is feasible if early detection can be made with limited spillage of the luminal content. Covered SEMS are the most successful endoscopic options. OTSC has been used in cases of small defects early in the postoperative course $(64,91)$. Major complications associated with SEMS are stent migration and risk of stricture formation secondary to ulceration, and TEF. EVT is a good option for patients with poor response to SEMS. Recent studies on EVT including a prospective study have shown promise in the management of gastroesophageal leaks with successful leak closure in $78-94 \%$ of cases. EVT involves repeated endoscopies for replacing sponges and monitoring (68).

Another common site of leak in the upper GI tract is gastrojejunal leak following RYGB or at staple line following sleeve gastrectomy. Various endoscopic techniques including OTSC, glue, endoscopic suturing and FCSEMS have been tried. FSEMS with anchoring sutures or clips are viable options to lower risk of stent migration. Other options for small leak closure include use of tissue sealants (67).

\section{Fistulas}

Presence of an epithelialized tract continuously exposed to GI secretions and the resulting inflammation pose significant challenges in the closure of GI fistulas. In addition, many fistulas are malignant or have associated radiation injury leading to altered anatomy and fibrotic changes that can further complicate the management. Various endoscopic techniques have been tried with variable success in managing GI fistulas. Esophago-respiratory fistulas (TEF and BEF) are among the most common upper GI fistulas. Majority of them are malignant, not amenable to surgery and are best managed by stents (19).

Gastric fistulas are rare but can be seen following PEG removal or more commonly following bariatric surgery in the percutaneous drain tracts $(27,29,30)$. Endoscopic clips, mostly OTSC has been successful in immediate closure of benign esophageal, gastric and colonic fistulas, although long-term success has either not been tested or disappointing with high rate of fistula recurrence (104). Of note, OTSC removal can be challenging (70,89,105-107).

Other less commonly used methods for managing GI fistula are endoscopic suturing and adhesive glue application. In a study by Sharaiha et al., endoscopic suturing led to initial clinical success in $62 \%$ of patients which was sustained in $60 \%$, most of the success being limited to patients undergoing early closure (64). Although 
endoscopic suturing can be used to close larger fistulas with short-term success, its long-term clinical efficacy is limited by lack of data and high recurrence in available retrospective studies.

New innovations in endoscopic closure devices and techniques have provided a promising less invasive approach to managing a wide range of GI disruptions. There has been a trend towards endoscopic management of GI perforations, leaks, and fistulas with good patient outcomes. Nevertheless, the decision of conservative, endoscopic, or surgical management has to be individualized. While endoscopic closure is highly successful if identified early and with minimal extra-luminal contamination, surgical or interventional radiology directed drainage may be warranted in cases of uncontained perforation or delayed recognition of defect with gross contamination. Thus, endoscopic management of GI defects entails involvement of a multidisciplinary team consisting of advanced endoscopists, surgery, and interventional radiology as appropriate. Early identification, appropriate antibiotic administration, drainage of any collection, and successful closure with appropriate endoscopic device and technique are paramount to a good patient outcome.

\section{Acknowledgements}

None.

\section{Footnote}

Conflicts of Interest: NA Kumta: Consultant for Apollo Endosurgery, Boston Scientific, Olympus. The other authors have no conflicts of interest to declare.

\section{References}

1. Sato H, Inoue H, Ikeda H, et al. Clinical experience of esophageal perforation occurring with endoscopic submucosal dissection. Dis Esophagus 2014;27:617-22.

2. Ojima T, Takifuji K, Nakamura M, et al. Complications of endoscopic submucosal dissection for gastric noninvasive neoplasia: an analysis of 647 lesions. Surg Laparosc Endosc Percutan Tech 2014;24:370-374.

3. Thirumurthi S, Raju GS. Management of polypectomy complications. Gastrointest Endosc Clin N Am 2015;25:335-57.

4. Zhang LP, Chang R, Matthews BD, et al. Incidence, mechanisms, and outcomes of esophageal and gastric perforation during laparoscopic foregut surgery: a retrospective review of 1,223 foregut cases. Surg Endosc 2014;28:85-90.

5. Nguyen NT, Goldman C, Rosenquist CJ, et al. Laparoscopic versus open gastric bypass: a randomized study of outcomes, quality of life, and costs. Ann Surg 2001;234:279-89; discussion 289-91.

6. Carrodeguas L, Szomstein S, Soto F, et al. Management of gastrogastric fistulas after divided Roux-en-Y gastric bypass surgery for morbid obesity: analysis of 1292 consecutive patients and review of literature. Surg Obes Relat Dis 2005;1:467-74.

7. Merchea A, Cullinane DC, Sawyer MD, et al. Esophagogastroduodenoscopy-associated gastrointestinal perforations: a single-center experience. Surgery 2010;148:876-80.

8. Zhou WZ, Song HY, Park JH, et al. Full-thickness esophageal perforation after fluoroscopic balloon dilation: incidence and management in 820 adult patients. AJR Am J Roentgenol 2015;204:1115-9.

9. Hagel AF, Naegel A, Dauth W, et al. Perforation during esophageal dilatation: a 10-year experience. J Gastrointestin Liver Dis 2013;22:385-9.

10. Sainathan S, Andaz S. A systematic review of transesophageal echocardiography-induced esophageal perforation. Echocardiography 2013;30:977-983.

11. Biancari F, D'Andrea V, Paone R, et al. Current treatment and outcome of esophageal perforations in adults: systematic review and meta-analysis of 75 studies. World J Surg 2013;37:1051-9.

12. Biancari F, Saarnio J, Mennander A, et al. Outcome of patients with esophageal perforations: a multicenter study. World J Surg 2014;38:902-9.

13. Markar SR, Mackenzie H, Wiggins T, et al. Management and outcomes of esophageal perforation: a national study of 2,564 patients in England. Am J Gastroenterol 2015;110:1559-66.

14. Rutegård M, Lagergren P, Rouvelas I, et al. Intrathoracic anastomotic leakage and mortality after esophageal cancer resection: a population-based study. Ann Surg Oncol 2012;19:99-103.

15. Kassis ES, Kosinski AS, Ross P Jr, et al. Predictors of anastomotic leak after esophagectomy: an analysis of the society of thoracic surgeons general thoracic database. Ann Thorac Surg 2013;96:1919-26.

16. Shin JH, Song HY, Ko GY, et al. Esophagorespiratory fistula: long-term results of palliative treatment with covered expandable metallic stents in 61 patients. 
Radiology 2004;232:252-9.

17. Chen YH, Li SH, Chiu YC, et al. Comparative study of esophageal stent and feeding gastrostomy/jejunostomy for tracheoesophageal fistula caused by esophageal squamous cell carcinoma. PLoS One 2012;7:e42766.

18. Balazs A, Kupcsulik PK, Galambos Z. Esophagorespiratory fistulas of tumorous origin. Non-operative management of 264 cases in a 20-year period. Eur J Cardiothorac Surg 2008;34:1103-7.

19. Kim KR, Shin JH, Song H-Y, et al. Palliative treatment of malignant esophagopulmonary fistulas with covered expandable metallic stents. AJR Am J Roentgenol 2009;193:W278-82.

20. Spigel DR, Hainsworth JD, Yardley DA, et al. Tracheoesophageal fistula formation in patients with lung cancer treated with chemoradiation and bevacizumab. J Clin Oncol 2010;28:43-8.

21. Gore E, Currey A, Choong N. Tracheoesophageal fistula associated with bevacizumab 21 months after completion of radiation therapy. J Thorac Oncol 2009;4:1590-1.

22. Reed MF, Mathisen DJ. Tracheoesophageal fistula. Chest Surg Clin N Am 2003;13:271-89.

23. Oda I, Suzuki H, Nonaka S, et al. Complications of gastric endoscopic submucosal dissection. Dig Endosc 2013;25 Suppl 1:71-8.

24. Armas Ojeda MD, Ojeda Marrero V, Roque Castellano C, et al. Duodenal perforations after endoscopic retrograde cholangiopancreatography. Cir Esp 2015;93:403-10.

25. Völgyi Z, Szenes M, Gasztonyi B. Types and management of perforations occurring during endoscopic retrograde cholangiopancreatography. Orv Hetil 2014;155:248-54.

26. Stapfer M, Selby RR, Stain SC, et al. Management of duodenal perforation after endoscopic retrograde cholangiopancreatography and sphincterotomy. Ann Surg 2000;232:191-8.

27. Falconi M, Pederzoli P. The relevance of gastrointestinal fistulae in clinical practice: a review. Gut 2001;49 Suppl 4:iv2-10.

28. Freeman HJ. Spontaneous free perforation of the small intestine in adults. World J Gastroenterol 2014;20:9990-7.

29. McElrath L, Pauli EM, Marks JM. Hernia formation and persistent fistula after percutaneous endoscopy gastrostomy: unusual complications of a common procedure. Am Surg 2012;78:E200-1.

30. Shellito PC, Malt RA. Tube gastrostomy. Techniques and complications. Ann Surg 1985;201:180-5.

31. Zachariah PJ, Lee WJ. Response to Comment: "LaparoEndoscopic Gastrostomy (LEG) Decompression: a Novel

(C) Translational Gastroenterology and Hepatology. All rights reserved.
One-Time Method of Management of Gastric Leaks Following Sleeve Gastrectomy". Obes Surg 2016;26:622-3.

32. Vermeer TA, Orsini RG, Daams F, et al. Anastomotic leakage and presacral abscess formation after locally advanced rectal cancer surgery: Incidence, risk factors and treatment. Eur J Surg Oncol 2014;40:1502-9.

33. Bemelman WA, Baron TH. Endoscopic Management of Transmural Defects, Including Leaks, Perforations, and Fistulae. Gastroenterology 2018;154:1938-1946.e1.

34. Dabizzi E, De Ceglie A, Kyanam Kabir Baig KR, et al. Endoscopic "rescue" treatment for gastrointestinal perforations, anastomotic dehiscence and fistula. Clin Res Hepatol Gastroenterol 2016;40:28-40.

35. Brown CVR. Small bowel and colon perforation. Surg Clin North Am 2014;94:471-5.

36. Lopez DE, Brown CVR. Diverticulitis: the most common colon emergency for the acute care surgeon. Scand J Surg 2010;99:86-9.

37. Paspatis GA, Dumonceau JM, Barthet M, et al. Diagnosis and management of iatrogenic endoscopic perforations: European Society of Gastrointestinal Endoscopy (ESGE) Position Statement. Endoscopy 2014;46:693-711.

38. Pitsinis V, Roberts P. Gastrocolic fistula as a complication of percutaneous endoscopic gastrostomy. Eur J Clin Nutr 2003;57:876-8.

39. Kuppusamy MK, Hubka M, Felisky CD, et al. Evolving management strategies in esophageal perforation: surgeons using nonoperative techniques to improve outcomes. J Am Coll Surg 2011;213:164-71; discussion 171-2.

40. Siu WT, Leong HT, Law BK, et al. Laparoscopic repair for perforated peptic ulcer: a randomized controlled trial. Ann Surg 2002;235:313-9.

41. Antoniou SA, Antoniou GA, Koch OO, et al. Metaanalysis of laparoscopic versus open repair of perforated peptic ulcer. JSLS 2013;17:15-22.

42. Baron TH, Wong Kee Song LM, Zielinski MD, et al. A comprehensive approach to the management of acute endoscopic perforations (with videos). Gastrointest Endosc 2012;76:838-59.

43. di Costanzo J, Cano N, Martin J, et al. Treatment of external gastrointestinal fistulas by a combination of total parenteral nutrition and somatostatin. JPEN J Parenter Enteral Nutr 1987;11:465-70.

44. Verlaan T, Voermans RP, van Berge Henegouwen MI, et al. Endoscopic closure of acute perforations of the GI tract: a systematic review of the literature. Gastrointest Endosc 2015;82:618-28.e5.

45. Stavropoulos SN, Modayil R, Friedel D. Closing 
perforations and postperforation management in endoscopy: esophagus and stomach. Gastrointest Endosc Clin N Am 2015;25:29-45.

46. Singhal S, Changela K, Papafragkakis H, et al. Over the scope clip: technique and expanding clinical applications. J Clin Gastroenterol 2013;47:749-56.

47. Banerjee S, Barth BA, Bhat YM, et al. Endoscopic closure devices. Gastrointest Endosc 2012;76:244-51.

48. Guarner-Argente C, Córdova H, Martínez-Pallí G, et al. Yes, we can: reliable colonic closure with the Padlock-G clip in a survival porcine study (with video). Gastrointest Endosc 2010;72:841-4.

49. Boumitri C, Kumta NA, Patel M, et al. Closing perforations and postperforation management in endoscopy: duodenal, biliary, and colorectal. Gastrointest Endosc Clin N Am 2015;25:47-54.

50. Yilmaz B, Unlu O, Roach EC, et al. Endoscopic clips for the closure of acute iatrogenic perforations: Where do we stand? Dig Endosc 2015;27:641-8.

51. Shi Q, Chen T, Zhong Y-S, et al. Complete closure of large gastric defects after endoscopic full-thickness resection, using endoloop and metallic clip interrupted suture. Endoscopy 2013;45:329-34.

52. van Halsema EE, van Hooft JE. Clinical outcomes of selfexpandable stent placement for benign esophageal diseases: A pooled analysis of the literature. World J Gastrointest Endosc 2015;7:135-53.

53. Swinnen J, Eisendrath P, Rigaux J, et al. Self-expandable metal stents for the treatment of benign upper GI leaks and perforations. Gastrointest Endosc 2011;73:890-9.

54. Verschuur EML, Repici A, Kuipers EJ, et al. New design esophageal stents for the palliation of dysphagia from esophageal or gastric cardia cancer: a randomized trial. Am J Gastroenterol 2008;103:304-12.

55. Uitdehaag MJ, van Hooft JE, Verschuur EML, et al. A fully-covered stent (Alimaxx-E) for the palliation of malignant dysphagia: a prospective follow-up study. Gastrointest Endosc 2009;70:1082-9.

56. Wilson JL, Louie BE, Farivar AS, et al. Fully covered self-expanding metal stents are effective for benign esophagogastric disruptions and strictures. J Gastrointest Surg 2013;17:2045-50.

57. Bor R, Fábián A, Bálint A, et al. Endoscopic management of complications of self-expandable metal stents for treatment of malignant esophageal stenosis and tracheoesophageal fistulas. Therap Adv Gastroenterol 2017;10:599-607.

58. Dai Y, Chopra SS, Kneif S, et al. Management of esophageal anastomotic leaks, perforations, and fistulae with self-expanding plastic stents. J Thorac Cardiovasc Surg 2011;141:1213-7.

59. Fujii LL, Bonin EA, Baron TH, et al. Utility of an endoscopic suturing system for prevention of covered luminal stent migration in the upper GI tract. Gastrointest Endosc 2013;78:787-93.

60. Shim CS, Cho YD, Moon JH, et al. Fixation of a modified covered esophageal stent: its clinical usefulness for preventing stent migration. Endoscopy 2001;33:843-8.

61. Kumta NA, Boumitri C, Kahaleh M. New devices and techniques for handling adverse events: claw, suture, or cover? Gastrointest Endosc Clin N Am 2015;25:159-68.

62. Hirdes MMC, Siersema PD, Houben MHMG, et al. Stent-in-stent technique for removal of embedded esophageal self-expanding metal stents. Am J Gastroenterol 2011;106:286-93.

63. Fiocca F, Cereatti F, Antypas P, et al. Argon plasma coagulation: a less-expensive alternative to the "stent-instent" technique for removal of embedded partially covered esophageal stents. Gastrointest Endosc 2016;83:453.

64. Sharaiha RZ, Kumta NA, DeFilippis EM, et al. A Large Multicenter Experience With Endoscopic Suturing for Management of Gastrointestinal Defects and Stent Anchorage in 122 Patients: A Retrospective Review. J Clin Gastroenterol 2016;50:388-92.

65. Coppola F, Boccuzzi G, Rossi G, et al. Cardiac septal umbrella for closure of a tracheoesophageal fistula. Endoscopy 2010;42 Suppl 2:E318-9.

66. Repici A, Presbitero P, Carlino A, et al. First human case of esophagus-tracheal fistula closure by using a cardiac septal occluder (with video). Gastrointest Endosc 2010;71:867-9.

67. Kotzampassi K, Eleftheriadis E. Tissue sealants in endoscopic applications for anastomotic leakage during a 25-year period. Surgery 2015;157:79-86.

68. Schorsch T, Müller C, Loske G. Endoscopic vacuum therapy of perforations and anastomotic insufficiency of the esophagus. Chirurg 2014;85:1081-93.

69. Strangio G, Zullo A, Ferrara EC, et al. Endo-sponge therapy for management of anastomotic leakages after colorectal surgery: A case series and review of literature. Dig Liver Dis 2015;47:465-9.

70. Gelbmann CM, Ratiu N, Rath H, et al. Use of selfexpandable plastic stents for the treatment of esophageal perforations and symptomatic anastomotic leaks. Endoscopy 2004;36:695-9.

71. Ott C, Ratiu N, Endlicher E, et al. Self-expanding Polyflex plastic stents in esophageal disease: various indications, 
complications, and outcomes. Surg Endosc 2007;21:889-96.

72. Freeman RK, Ascioti AJ, Wozniak TC. Postoperative esophageal leak management with the Polyflex esophageal stent. J Thorac Cardiovasc Surg 2007;133:333-8.

73. Kiev J, Amendola M, Bouhaidar D, et al. A management algorithm for esophageal perforation. Am J Surg 2007;194:103-6.

74. Johnsson E, Lundell L, Liedman B. Sealing of esophageal perforation or ruptures with expandable metallic stents: a prospective controlled study on treatment efficacy and limitations. Dis Esophagus 2005;18:262-6.

75. Fischer A, Thomusch O, Benz S, et al. Nonoperative treatment of 15 benign esophageal perforations with self-expandable covered metal stents. Ann Thorac Surg 2006;81:467-72.

76. Tuebergen D, Rijcken E, Mennigen R, et al. Treatment of thoracic esophageal anastomotic leaks and esophageal perforations with endoluminal stents: efficacy and current limitations. J Gastrointest Surg 2008;12:1168-76.

77. van Heel NC, Haringsma J, Spaander MC, et al. Shortterm esophageal stenting in the management of benign perforations. Am J Gastroenterol 2010;105:1515.

78. Schorsch T, Müller C, Loske G. Endoscopic vacuum therapy of anastomotic leakage and iatrogenic perforation in the esophagus. Surg Endosc 2013;27:2040-5.

79. Minami S, Gotoda T, Ono H, et al. Complete endoscopic closure of gastric perforation induced by endoscopic resection of early gastric cancer using endoclips can prevent surgery (with video). Gastrointest Endosc 2006;63:596-601.

80. Toyokawa T, Inaba T, Omote $S$, et al. Risk factors for perforation and delayed bleeding associated with endoscopic submucosal dissection for early gastric neoplasms: analysis of 1123 lesions. J Gastroenterol Hepatol 2012;27:907-12.

81. Jeon SW, Jung MK, Kim SK, et al. Clinical outcomes for perforations during endoscopic submucosal dissection in patients with gastric lesions. Surg Endosc 2010;24:911-6.

82. Voermans RP, Le Moine O, Von Renteln D, et al. Efficacy of endoscopic closure of acute perforations of the gastrointestinal tract. Clin Gastroenterol Hepatol 2012;10:603-8.

83. Hagel AF, Naegel A, Lindner AS, et al. Over-thescope clip application yields a high rate of closure in gastrointestinal perforations and may reduce emergency surgery. J Gastrointest Surg 2012;16:2132-8.

84. Knudson K, Raeburn CD, McIntyre RC, et al. Management of duodenal and pancreaticobiliary perforations associated with periampullary endoscopic procedures. Am J Surg 2008;196:975-81; discussion 981-2.

85. Parodi A, Repici A, Pedroni A, et al. Endoscopic management of GI perforations with a new over-thescope clip device (with videos). Gastrointest Endosc 2010;72:881-6.

86. Al Ghossaini N, Lucidarme D, Bulois P. Endoscopic treatment of iatrogenic gastrointestinal perforations: an overview. Dig Liver Dis 2014;46:195-203.

87. Cho J, Sahakian AB. Endoscopic Closure of Gastrointestinal Fistulae and Leaks. Gastrointest Endosc Clin N Am 2018;28:233-49.

88. Mukewar S, Kumar N, Catalano M, et al. Safety and efficacy of fistula closure by endoscopic suturing: a multicenter study. Endoscopy 2016;48:1023-8.

89. Law R, Wong Kee Song LM, Irani S, et al. Immediate technical and delayed clinical outcome of fistula closure using an over-the-scope clip device. Surg Endosc 2015;29:1781-6.

90. Mönkemüller K, Peter S, Toshniwal J, et al. Multipurpose use of the "bear claw" (over-the-scope-clip system) to treat endoluminal gastrointestinal disorders. Dig Endosc 2014;26:350-7.

91. van Boeckel PG, Dua KS, Weusten BLAM, et al. Fully covered self-expandable metal stents (SEMS), partially covered SEMS and self-expandable plastic stents for the treatment of benign esophageal ruptures and anastomotic leaks. BMC Gastroenterol 2012;12:19.

92. Tsunada S, Ogata S, Ohyama T, et al. Endoscopic closure of perforations caused by EMR in the stomach by application of metallic clips. Gastrointest Endosc 2003;57:948-51.

93. Singhal S, Atluri S, Changela K, et al. Endoscopic closure of gastric perforation using over-the-scope clip: a surgerysparing approach. Gastrointest Endosc 2014;79:23.

94. Jirapinyo P, Watson RR, Thompson CC. Use of a novel endoscopic suturing device to treat recalcitrant marginal ulceration (with video). Gastrointest Endosc 2012;76:435-9.

95. Kobayashi M, Sumiyama K, Ban Y, et al. Closure of iatrogenic large mucosal and full-thickness defects of the stomach with endoscopic interrupted sutures in in vivo porcine models: are they durable enough? BMC Gastroenterol 2015;15:5.

96. Matthes K, Jung Y, Kato M, et al. Efficacy of full-thickness GI perforation closure with a novel over-the-scope clip application device: an animal study. Gastrointest Endosc 2011;74:1369-75.

97. Raju GS, Saito Y, Matsuda T, et al. Endoscopic 
management of colonoscopic perforations (with videos). Gastrointest Endosc 2011;74:1380-8.

98. Kim JH, Yoo BM, Kim JH, et al. Management of ERCPrelated perforations: outcomes of single institution in Korea. J Gastrointest Surg 2009;13:728-34.

99. Haider S, Kahaleh M. The use of endoscopic clipping devices in the treatment of iatrogenic duodenal perforation. Gastroenterol Hepatol (N Y) 2010;6:660-1.

100. Tam MS, Abbas MA. Perforation following colorectal endoscopy: what happens beyond the endoscopy suite? Perm J 2013;17:17-21.

101. Cho SB, Lee WS, Joo YE, et al. Therapeutic options for iatrogenic colon perforation: feasibility of endoscopic clip closure and predictors of the need for early surgery. Surg Endosc 2012;26:473-9.

102. Trecca A, Gaj F, Gagliardi G, et al. Our experience with endoscopic repair of large colonoscopic perforations and review of the literature. Tech Coloproctol 2008;12:315.

103. Díez-Redondo P, Blanco JI, Lorenzo-Pelayo S, et al. A

doi: $10.21037 / \operatorname{tgh} .2018 .10 .09$

Cite this article as: Singh RR, Nussbaum JS, Kumta NA. Endoscopic management of perforations, leaks and fistulas. Transl Gastroenterol Hepatol 2018;3:85. novel system for endoscopic closure of iatrogenic colon perforations using the Ovesco clip and omental patch. Rev Esp Enferm Dig 2012;104:550-2.

104. Manta R, Caruso A, Cellini C, et al. Endoscopic management of patients with post-surgical leaks involving the gastrointestinal tract: A large case series. United European Gastroenterol J 2016;4:770-7.

105. Haito-Chavez Y, Ngamruengphong S, Chen YI, et al. Novel hybrid technique for closure of refractory gastrocutaneous fistula: endoscopically guided percutaneous suturing. Gastrointest Endosc 2017;85:252-3.

106. Shehab HM, Hakky SM, Gawdat KA. An Endoscopic Strategy Combining Mega Stents and Over-The-Scope Clips for the Management of Post-Bariatric Surgery Leaks and Fistulas (with video). Obes Surg 2016;26:941-8.

107.Kapadia S, Nagula S, Kumta NA. Argon plasma coagulation for successful fragmentation and removal of an over-the-scope clip. Dig Endosc 2017;29:820-1. 